\title{
O ATAQUE À "BOA TERRA": SAMBISTAS, PAGODEIROS BAIANOS E SUA MÚSICA NA MIRA DA PROVOCAÇÃO, DA GALHOFA E DO PRECONCEITO
}

\author{
Gustavo Gobbi Novaes ${ }^{1}$
}

\begin{abstract}
Resumo: $\mathrm{O}$ presente artigo busca analisar os sentidos de discursos provocativos e preconceituosos contra os sambistas e pagodeiros baianos, por parte de agentes do mundo do samba, como músicos, jornalistas e críticos culturais, aproveitando parte de pesquisa prévia para projeto de pesquisa, aprovado no Programa de Pós-Graduação em História, da Universidade Federal da Bahia, somado a pesquisas posteriores. Parte-se de 1918, com a polêmica entre o sambista carioca Sinhô e Pixinguinha e sua turma, trazendo exemplos de enunciados preconceituosos na década de 30. Em outro recorte, de 1990 em diante, expõe-se alguns exemplos de ataques discursivos ao samba e ao pagode baiano por parte de músicos e jornalistas contemporâneos. Os processos de construção de identidades e tradições fundamentam teoricamente a abordagem, a partir de autores como Stuart Hall, Roger Chartier, Eric Hobsbawm, dentre outros. Utiliza-se, ainda, da análise do discurso, proposta por Hall. Se, por um lado, buscou-se sobrepor o nascente samba urbano carioca aos outros sambas regionais; por outro, o pagode baiano tem sido alvo de desqualificações, desde sua dimensão mercadológica até os seus usos, vivências e práticas.
\end{abstract}

Palavras-Chave: Samba de roda. Pagode baiano. Discursos. Preconceito.

\section{L'AGRESSION À LA “BONNETERRE”: SAMBISTES, PAGODEIROS BAHIANAIS ET LEUR MUSIQUE COMME CIBLE DE LA PROVOCATION ET DU PRÉJUGÉ}

Résumé: Le présent article analisera les sens des discours provocateurs et péjoratifs contre les sambistes et pagodeiros à Bahia, pour acteurs au monde du samba, comme musiciens, journalistes et criticiens culturels, à partir d'utilisastion de part des études précédents pour projet de recherche, approuvé en Cours de Doctorat en Histoire à UFBa, et recherches ultérieurs. D'abord, la recherche commencerá en 1918 avec la polémique entre le sambiste à Rio de Janeiro Sinhô et Pixinguinha et ton groupe, présentant exemples de discours

\footnotetext{
${ }^{1}$ Mestre em Ciências Sociais - Universidade Federal de Juiz de Fora (UFJF). Doutorando em História Social -Universidade Federal da Bahia (UFBa).gustavogobbinovaes@ymail.com.
} 
péjoratifs, dans les anées 30. D'outre part, puis 1990, s'enregistrera quelques exemples d'offenses discoursives au samba et le pagode à Bahia pour les musiciens et journalistes actuels. Les processus de costruction d'identitées et des traditions soutenant téoriquement l'approche, avec chercheurs comme Stuart Hall, Roger Chartier, Eric Hobsbawm, entre autres. S'utiliserá de l'analyse du discours a proposé pour Hall. D'une part, le samba débutant à Rio a été construit comme supérieur à d'outres sambas régionales, d'outre part, le pagode à Bahia a été cible des disqualifications, puis sa taille commerciale jusqu'à ses expériences et pratiques.

Mots-clés: Samba de roda. Pagode à Bahia. Discours. Préjugé.

\section{Introdução}

A partir de pesquisa prévia realizada para a confecção de projeto de doutorado, o qual foi submetido e aprovado no Programa de Pós-graduação em História da Universidade Federal da Bahia, surgiu a base para a construção deste artigo. Sua temática funda-se nas tensões narrativas entre agentes do mundo do samba baiano e carioca. Dentre tais agentes, sambistas e intelectuais êmicos ${ }^{2}$ lançaram discursos, já nas primeiras décadas do século $\mathrm{XX}$, com posturas identitárias próprias e com construções de tradições ligadas aos seus respectivos lugares de origem. Nessa pesquisa prévia realizada, foi possível observar em músicas, matérias jornalísticas, entrevistas, dentre outras fontes, discursos que construíram uma determinada sobreposição do nascente samba urbano carioca às outras manifestações regionais de samba. Somado a esta, a leitura posterior de diferentes fontes a respeito da formação do chamado "pagode baiano" conduziu à identificação de outras formas narrativas marcadas pela

\footnotetext{
2 Fernandes (2010) aponta para os processos de formação desses intelectuais, que atuaram como cronistas, críticos culturais e jornalistas "especializados" nas temáticas de carnaval e samba. Nomes como Vagalume, Almirante, Orestes Barbosa, Animal, dentre outros, produziram obras sobre a história da música popular, sobre os sambistas e suas vidas, ao mesmo tempo em que atuaram ativamente nas redações de diversos periódicos, produzindo crônicas e críticas destinadas a exaltar ou atacar sambistas e o mundo do samba; não deixaram, por outro lado, de se envolver ativamente no meio boêmio, seja a partir de parcerias na composição de sambas, seja participando de noitadas animadas regadas a rodas de samba. Nesse sentido, falar desses intelectuais significa trazer à tona a produção textual desses jornalistas, cronistas e críticos culturais que se envolveram diretamente com o mundo do samba, no momento em que fervilhava o debate nacional, com a modernização urbana e o surgimento de novas tecnologias de mídia.
} 
provocação e pelo preconceito por parte de músicos e jornalistas contemporâneos.

Foi no Rio de Janeiro do início do século XX, frequentando as casas das tias baianas ${ }^{3}$, que figuras como Pixinguinha, João da Baiana, Heitor dos Prazeres, Ernesto dos Santos (o Donga), dentre outros, tornaram-se importantes no meio musical carioca. As casas dessas tias constituíam-se em lugares onde eram reafirmados valores e símbolos da comunidade negra baiana e carioca (LIMA, s/d., p. 6). Construíram-se como lugares de socialização e de reprodução de padrões culturais próprios, entrecruzando valores religiosos e festivos. A partir dessas manifestações culturais, criadoras de novas formas estéticas, houve para esses artistas negros e pobres a abertura para a trama da indústria cultural (SODRÉ, 1998). Observa-se no Rio, capital do país à época, o surgimento, a partir de 1920, das rádios, além de gravadoras, como a RCA, Casa Edison, Parlophon, Columbia, dentre outras (LEAL, 2016, p. 49). Nesse momento, casos de tensões musicais, algumas gravadas em disco, envolveram a provocação e o preconceito contra baianos.

A música Quem são eles? primeiro sucesso do sambista carioca Sinhô (José Barbosa da Silva), - que, de acordo com Sandroni (2001, p. 125), “fez dos ataques aos baianos um de seus temas prediletos" -, foi composta em 1918 e desencadeou uma rixa com Pixinguinha, China, Donga e sua turma. Estes, a partir dessa e de outras composições provocativas, fizeram questão de revidar e criaram músicas de resposta. Por outro lado, houve narrativas que trabalharam a exaltação de seus lugares de origem como terra de gente bamba, trazendo para a glória desses lugares o sucesso e o talento de grandes sambistas. Com isso, deu-se a formação de tradições a partir da exaltação de sambistas e suas cidades, como lugares de samba e de bons compositores.

De acordo com Lima (2013, p. 124), quando se trata das obras e esforços de intelectuais que se debruçaram sobre samba e sambistas, não é incomum uma reflexão de caráter etapista, que remete a uma "evolução" da história do samba do Rio de Janeiro, definido como nacional e urbano,

\footnotetext{
3 Majoritariamente, eram essas mulheres de origem baiana que estavam à frente das casas que abrigavam reuniões familiares promotoras de eventos de socialização da comunidade negra local, mas admitindo, também, em seus interiores, a presença de sujeitos brancos de outros estratos sociais. A Tia Ciata tornou-se a mais famosa entre as tias conhecidas, possuindo uma casa nos arredores da Praça Onze. Tais casas funcionavam, ainda, como lugares estratégicos de resistência negra contra a perseguição política e policial (SODRÉ, 1998).
} 
defendendo "uma história do samba que teria se iniciado na Bahia tradicional e prosseguido no Rio de Janeiro moderno e mestiço, a partir do final do século XIX". O samba de roda como prática musical, coreográfica, poética e festiva presente em todo o estado da Bahia, particularmente na região do Recôncavo (IPHAN, 2006), tem sido visto por alguns intelectuais como um substrato embrionário de um samba que foi "melhorado" no Rio de Janeiro - àquela época, capital do país. Fundou-se um samba carioca, elevado a produto cultural nacional, rebaixando-se a mera expressão regional as outras manifestações de samba em São Paulo, Sergipe, Pernambuco, Bahia, dentre outros (MOURA, 2001).

Por outro lado, o chamado pagode baiano - inaugurado na Bahia no final dos anos 1990, com influências do samba de roda baiano, do pagode e do samba carioca, cujo principal expoente foi a banda É $o$ Tchan - tem sido alvo de ataques preconceituosos por parte de jornalistas e músicos contemporâneos (FERNANDES, 2010; MOURA, 2001; NASCIMENTO, 2012). Este sofre duplamente o preconceito: tanto de agentes críticos locais quanto de músicos e jornalistas de outras regiões que, imbuídos de postura por vezes elitista, desfiam ataques ácidos ao estilo4. Consideram-no como música de caráter mercadológico e de baixa qualidade técnica e estética, colocando-o na mesma linha de julgamento que fazem ao pagode carioca, o axé music e o sertanejo.

A despeito da amostragem que será apresentada a seguir, não se pode afirmar que as relações entre esses agentes do mundo do samba tenham sido marcadas apenas por tais tensões. Sabe-se que a cordialidade e a reciprocidade elogiosa entre os artistas e críticos culturais mostram-se mais frequentes que os momentos em que se desatam desentendimentos e enunciados agressivos. Contudo, tal abordagem objetiva pôr em foco os momentos em que as narrativas se revelaram provocativas, bairristas ou preconceituosas, a partir de fontes como sambas compostos, falas de sambistas em entrevistas, matérias jornalísticas e obras de intelectuais

\footnotetext{
${ }^{4} \mathrm{O}$ pagode baiano, assim como o samba-reggae, dentre outros ritmos musicais que podem figurar na cena cultural baiana, compõem, para Moura (2001), estilos conformadores do amplo repertório musical e coreográfico da axé music. De acordo com o autor, a axé music não se trata de mero estilo musical ou somatório da produção de determinado grupo artístico. Trata-se de uma interface que relaciona estilos, com estéticas próprias, que deram ensejo ao chamado Carnaval Baiano.
} 
ligados ao mundo do samba. Nesse artigo, considerável parte dos discursos provocativos ou preconceituosos é desferida por músicos e intelectuais inseridos no contexto cultural e jornalístico carioca, mas apontou-se também enunciados de teor agressivo dos próprios jornalistas e músicos baianos, principalmente no tocante ao pagode baiano.

Nesse sentido, em um primeiro momento esta análise se iniciará nos idos de 1918, quando se estabeleceu uma arenga musical entre o sambista carioca Sinhô e Pixinguinha e seus parceiros, passando por alguns exemplos de manifestações de caráter provocativo e preconceituoso. Em um segundo momento será dado um salto temporal, a partir da década de 1990 em diante, com o intuito de expor outros exemplos, revelando o quanto o preconceito às manifestações tradicionais de samba da Bahia e ao recente pagode baiano permanece vivo nas falas e textos de agentes envolvidos, direta ou indiretamente, no universo musical do samba.

Com base no exposto até esse momento e considerando os enunciados de sambistas e intelectuais êmicos, propõe-se a seguinte questão: quais são os sentidos dos discursos que desfiam provocações, galhofas e preconceitos contra a Bahia, os baianos e sua música, encetados por esses agentes ligados ao mundo do samba?

Para responder a essa questão, torna-se necessário trazer os sambistas, intelectuais êmicos e jornalistas contemporâneos que se envolveram na produção de enunciações provocativas e preconceituosas, com relação à Bahia, os baianos e sua música. Trata-se de se debruçar sobre as produções discursivas desses agentes, na medida em que é por meio dos discursos presentes na sociedade que as pessoas tornam o mundo significativo e podem, assim, atribuir sentido ao mesmo. Desta maneira, atribui-se ao ofício do trabalho empírico especificar quais leituras um determinado texto pode estar operando (HALL, 2003). Pontua-se, como estratégia de análise, a análise do discurso ${ }^{5}$, de Stuart Hall (2003).

\footnotetext{
${ }^{5}$ Trata-se, de acordo com o autor, de posicionar o texto como um objeto de pesquisa, identificando nele o processo de codificação do qual foi objeto, para, em seguida, desmontar analiticamente seus sentidos, dentro de um processo de decodificação. Para fins de análise textual, o pesquisador assume a posição de decodificador, daquele que possibilitará a criação de um sentido analítico para a discursividade dos agentes, gerando outro campo semântico diferente daquele de seus emissores. É na decodificação que se abre o discurso para a análise interpretativa das significações possíveis da autorrepresentação de indivíduos e grupos.
} 
Analisar estas narrativas provocativas e preconceituosas significa dar sentido a discursos por meio de uma ótica epistemológica que se funda no estudo dos processos de construção das identidades. Identidade, por sua vez, só pode ser pensada levando em consideração a diferença, ou seja, é na definição e demarcação do diferente que a identidade pode fixar-se (HALL, 2011; POLLAK, 1992; WOODWARD, 2009). A construção de uma autoimagem sempre está balizada em função do outro. Desse modo, chega-se à definição de uma imagem "de si, para si e para os outros" (POLLAK, 1992, p. 204).

Dentro desse processo de definição de uma autoimagem, símbolos, referências e práticas sociais próprias passam a ser valorizadas e/ou exaltadas, podendo formar tradições que se revelam a partir de narrativas inculcadas, ensejando uma continuidade com um passado apropriado. Tradição sugere, de acordo com Hobsbawm e Ranger (2014), a repetição de valores a partir da consubstanciação com um passado histórico. Para os autores, por dentro das tradições há tanto elementos fragmentários resgatados de uma história pregressa quanto processos narrativos criados ou inventados - a fim de garantir a consolidação dessas tradições. Nesse sentido, instituições e agentes sociais buscam símbolos, eventos, valores e sujeitos que possam servir como marcas de uma tradição. É possível evidenciar processos narrativos de construção e consolidação de elementos de uma tradição sambista em cidades como o Rio de Janeiro, ou regiões, como a do Recôncavo baiano.

Assim sendo, entre grupos identitariamente distintos podem ser construídas práticas balizadas por representações ${ }^{6}$, muitas vezes contraditórias e em conflito, a partir das quais os indivíduos e grupos conferem sentido às suas realidades (CHARTIER, 1991). Na medida em que os sujeitos falam partindo de posições históricas e culturais específicas, narrativas podem ser contestadas e há tentativas de desestabilizar determinada posição e discurso (SILVA, 2009). Pode nascer daí a postura preconceituosa que inflige ao outro a estereotipia, o estigma $^{7}$ e a

${ }^{6}$ De acordo com Chartier (1991, p. 183), representações são "práticas que visam fazer reconhecer uma identidade social, a exibir uma maneira própria de ser no mundo, a significar simbolicamente um estatuto e uma posição".

7 Trata-se, como coloca Goffman (1988), da demarcação de atributos negativos e/ou depreciativos, que estigmatizam um determinado grupo ou indivíduo em detrimento de outro grupo ou indivíduo. A base de sustentação do estigma é a própria discriminação, que define concepções muitas vezes deliberadas do 
desqualificação. Isso leva a considerar Guimarães (2000, p. 1) quando afirma que: "O preconceito contra os baianos, paraíbas e nordestinos é dos mais fortes e persistentes no Brasil contemporâneo, só rivalizado pelo preconceito racial". No entanto, para o autor, a visualização desse preconceito começa muito antes na história do país, mais precisamente a partir da ascensão da República.

\section{A Bahia, os baianos e sua música na mira da provocação, da galhofa e do preconceito}

Atualmente, quando se fala em samba e carnaval, o movimento "natural" que se faz é pensar imediatamente no Rio de Janeiro. O fortíssimo apelo que o carnaval e o samba trazem a reboque direciona os nossos olhares para esta cidade. O Rio exerceu seu protagonismo não somente pela sua centralidade dentro do projeto político-pedagógico estatal, iniciado no século $\mathrm{XX}$, com processos de invenção de uma ideia de nação e de povo brasileiro, mas foi capaz de se inventar como cidade maravilhosa, única portadora da produção do maior espetáculo da terra, ratificando a sua "vocação turística" e fazendo disseminar aspectos do seu modelo cultural para outros lugares do país (MOURA, 2001, p. 107).

De acordo com Moura (2001), há cidades que se constituem como centros, núcleos, emblemas de processos que deságuam no estabelecimento de uma nação, de um estado, ou de um gênero musical. É o caso de New Orleans, Roma, Paris, Rio de Janeiro etc. Com isso, de acordo com Hobsbawm e Ranger (2014), remete-se a discursos criadores de valores e símbolos desejados e repetidos, que resgatam fragmentos de suas histórias, mas, também, inventam-se como lugares com características específicas. Isso pode ser evidenciado em fontes diversas; a centralidade das abordagens sobre música popular brasileira, entre intelectuais êmicos e também acadêmicos, paira

desejo de inferiorização e estereotipação do outro; capaz, ainda, de impedir ou reduzir as chances de vida do grupo estigmatizado. O autor demarca alguns tipos de estigmas, dentre os quais importa mais, para fins desta análise, os estigmas de raça, nação e religião, sofridos de forma profunda entre a vasta população negra brasileira, escravizada no passado e preterida socioeconomicamente, desde a abolição. As religiões de matriz africana, no Brasil, foram e ainda são alvos de perseguição e discriminação, por parte de não adeptos, gerando tensões visíveis e, por vezes, violentas. Há ainda o estigma de nação, que se refere à demarcação de origem e pode ser relacionado ao preconceito direcionado, atualmente, ao nordestino, principalmente por parte dos habitantes das regiões sul e sudeste do país. 
sobre esta cidade. Ou seja, o Rio elaborou o Rio de forma singular e, com contornos reconhecíveis, desabrochou como cidade do samba (MOURA, 2001).

Enquanto a cidade do Rio de Janeiro ia se tornando a "cidade brasileira mais representativa no cenário nacional” (LEAL, 2016, p. 48), tanto pela sua condição política de capital quanto por dar espaço para o caldo cultural de elementos negros, a partir dos batuques, das novas experiências rítmicas nas casas das tias baianas, dos ranchos, sociedades carnavalescas e escolas de samba; a Bahia e sua capital, por sua vez, foram se esvaziando de prestígio, sendo pintadas, desde a ascensão da República - racional, voltada ao moderno e ao científico - como representativa do arcaico, do tradicional e antimoderno; enquanto seu povo, estereotipado como "atrasado, ignorante, démodé e ridículo em suas pretensões de civilidade” (GUIMARÃES, 2000, p. 2). Para endurecer tal estereotipia, veio, ainda, o estigma da raça: as teorias raciais europeias inundaram a academia brasileira e a figura do mestiço ficou atrelada à noção de atraso, lascívia e preguiça. De acordo com Guimarães (2000, p. 4), “A Bahia era a mulatice. Sem imigrantes europeus novos [...]. Era o velho caldeirão racial parado no tempo, a receber o influxo demográfico dos negros". Na virada do século XIX para o XX, chegou-se à composição do estigma que nutriu o primeiro preconceito contra os baianos: a decadência, o barroco, a mulatice. Nos anos 1930, houve esforços na tentativa de sintonizar a Bahia com o projeto de construção de uma cultura nacional. Uma parte da elite intelectual baiana buscou valorizar elementos simbólicos da cultura afro-brasileira, elementos estes também utilizados por artistas como Carmem Miranda, visando a se reconhecer que:

[...] como no caso do samba, a cultura baiana era a cultura brasileira. A Bahia nunca se retratou como diferente do Brasil; em vez disso, uma elaboração da identidade cultural baiana foi usada para remover a Bahia das margens e inseri-la de volta na identidade nacional (ROMO, 2010, p. 134).

No processo de construção do Rio como centro cultural e lugar de samba, de gente bamba e familiarizada ao batuque, pôde-se observar jornais cariocas pontuando as qualidades sambistas de seu povo. O Jornal do Brasil, por exemplo, edição de domingo de 3 de janeiro de 1937, trouxe a matéria Samba, de Jônatas Dias de Castro (p. 18), que afirmou: 
O carioca é do samba; [...] a razão por que para o carioca, o seu apropósito é um samba! [...] em qualquer lugar o carioca mostra-se um "crack" na "batucada”; [...] a Cidade Maravilhosa é o centro artístico que irradia arte para todo o Brasil [...].

Por outro lado, os baianos não deixaram de referenciarem-se como sujeitos bambas e talentosos compositores. A Bahia, por sua vez, pintou-se como terra de samba e bons musicistas. Nesse processo constitutivo de produção de uma Bahia musicalmente ativa, o jornal baiano O Imparcial enalteceu o sambista baiano Assis Valente, em 1935, em matéria intitulada Quem nasce na Bahia é bamba...

Assis Valente, o "bamba" que deixou a "boa-terra" e foi fazer o "desacato" na capital da república veio rever a sua Bahia que ele tanto tem enaltecido nas suas canções populares, que andam na boca de toda a gente, de norte a sul do paiz. Assis Valente é um jovem victorioso. Daqui sahindo ainda obscuro, chegou ao Rio e de labuta em labuta, batalhando sempre, conseguiu conquistar uma série de triumphos, que, hoje, lhe adornam o nome já conhecidíssimo em todo o Brasil. E essas victorias elle conseguiu a custo do talento que possue, de inspirado compositor popular. Mostrando, deveras, o que affirmou na sua canção de estréia. Um samba que ainda não foi esquecido, cantando a Bahia que elle nunca esquece: "Bahia terra do meu samba! Quem nasce na Bahia é bamba, bamba [...]" (O Imparcial, p. 1, 8 mar. 1935).

Tais narrativas revelam essa construção nas quais cariocas e baianos se colocam como detentores de grande inclinação para o samba, evocando seus lugares como de produção "musical-sambista" de sucesso. É recorrente nas fontes de jornais e revistas esse processo de definição de uma autoimagem específica, desejada, baseada em representações narrativas que apresentam elementos de enaltecimento do lugar de origem, com base em distintivos como a Bahia "boa terra", ou o Rio "cidade maravilhosa". Além de baianos e cariocas procurarem, com essas práticas, a fundação e reprodução de tradições (HOBSBAWM; RANGER, 2014), trata-se, como afirma Hall (2009), de uma busca de recursos simbólicos na linguagem e na cultura para a construção de identidades, para, por sua vez, construir uma imagem não somente para si, mas também, para a apreciação do “outro" (POLLAK, 1992).

No caso do Rio de Janeiro, por exemplo, houve a composição de músicas cujo discurso foi capaz de centralizar a cidade como lugar onde se poderia ouvir um samba "verdadeiramente" brasileiro. Uma composição de 
Oswaldo Silva destacou, em alguns versos, essa afirmativa de que o carioca é bamba e que o samba de fato brasileiro era aquele feito no Rio de Janeiro, como apontado no trecho a seguir: "O samba p'ra ser bem brasileiro, meu bem / Tem que ser feito (cá) no Rio de Janeiro [...] / E podem mesmo falar mal, mas no samba ele é bamba [...]". Contudo, a produção musical sambista carioca não para somente em enunciados versificados destinados a exaltar sua "cidade maravilhosa" e seus "craques na batucada". Algumas composições de Sinhô revelaram disputas musicais e detiveram-se a tecer provocações e preconceitos contra os baianos e a Bahia (CUNHA, 2015). Tal como Sandroni (2001) coloca, o sambista, apesar de ter frequentado a casa da famosa Tia Ciata, polemizou com o grupo de sambistas baianos, composto por Pixinguinha, Donga, China, Cícero de Almeida, dentre outros.

Nesse contexto político em que fervilhava o debate nacional, somado ao nascente mercado das gravações em disco e da difusão do rádio, surgiram vários conflitos entre diferentes grupos sambistas de origem negra, com padrões criativos diferentes, ocasionando disputas por legitimidade e reconhecimento. Sinhô tinha claro interesse em ser considerado por cronistas de jornais e gravadoras; buscava ser reconhecido pelo público. Diferenças entre posturas profissionais e uma "identidade musical não totalmente compartilhada" (CUNHA, 2005, p. 558) revelaram-se entre Sinhô e estes outros nomes identificados ao grupo do samba baiano. Há, nesse momento, um contexto de conflitos entre uma geração de músicos que buscava construir uma identidade carioca diferenciada, e os músicos baianos, cuja matriz identitária assentava-se pela manutenção de seus valores, interligando música, festa e religião (CUNHA, 2005).

Monteiro (2010, p. 94) coloca que as canções de Sinhô "funcionam como elemento de comunicação de Sinhô com outros sambistas, com outros grupos sociais e com a sociedade de um modo geral". De acordo com a autora, suas composições podem ser estruturadas, em alguns casos, na forma de diálogos, mantendo seus perfis mensageiros de recados e provocações a outros sambistas. A tonalidade provocativa que chama à disputa os baianos está posta nos versos da música Fala Meu Louro.

A Bahia não dá mais coco
para botar na tapioca
Pra fazer o bom mingau
para embrulhar o carioca




\author{
Papagaio louro do bico dourado \\ Tu falavas tanto \\ qual a razão que vives calado \\ Não tenhas medo \\ coco de respeito \\ Quem quer se fazer não pode \\ Quem é bom já nasce feito
}

Fruto de uma polêmica que envolve acusações de plágio da parte de Sinhô, esse samba seria uma sátira a Rui Barbosa e sua derrota em pleito eleitoral, mas apresenta a chave de versos "A Bahia não dá mais côco / Para embrulhar o carioca", bastante provocativa aos baianos, fazendo parecer que o samba destes seria sem importância no Rio de Janeiro e não "dobraria" mais os cariocas. Por outro lado, lança dúvidas sobre a competência musical dos baianos, que desejariam "se fazer" compositores respeitados, sem perceber que "Quem é bom já nasce feito". Na esteira dessas disputas musicais, Sinhô compôs Quem são eles? samba de 1918 onde os primeiros versos são conhecidos por fazer referência negativa à Bahia: “A Bahia é boa terra / Ela lá e eu aqui [...]". Entendida como uma provocação, essa música não ficou sem resposta e, nesse jogo dialógico, houve reação do grupo dos baianos, que zombou de Sinhô na música Já te digo, cujo trecho assim dizia: “[...] Ele é alto, magro e feio / É desdentado / Ele fala do mundo inteiro [...]".

Há, ainda, casos de subsunção da importância e da participação baiana na formação da música popular carioca do início do século XX, buscando-se priorizar somente determinado grupo de sambistas. De acordo com Sandroni (2001), enquanto Orestes Barbosa, em sua obra Samba, denotando modernidade burguesa e urbana à formação do samba carioca, dedicou significativa atenção à contribuição de compositores cariocas, citando somente de passagem a participação dos baianos, sem menção à Bahia nos eventos narrados; Francisco Guimarães (1933, p. 31-32), o Vagalume, em sua obra Na roda do samba, recaiu no discurso tradicionalista sobre o mesmo, onde se percebe a valorização do rural, visto como primordial ou folclórico, fruto de um movimento inicial em direção ao desenvolvimento de um samba posterior, moderno e urbano. Vagalume afirmou que o samba "primitivo" seria o samba raiado, fincado no mundo rural baiano. "Evoluiu", depois, para samba chula. Uma vez no Rio de Janeiro, "progrediu” e passou a ser feito nos morros, tomando, segundo ele, a forma "verdadeira" com o ritmo de partido 
alto. Nesse caso, Vagalume não nega a "origem" baiana do samba, mas a vê como "primitiva", transformando-se, posteriormente, na sua forma "civilizada" a partir dos morros cariocas e com as escolas de samba.

O Rio de Janeiro, enquanto palco de significativas transformações socioculturais do início do século XX, presenciou a modernização nas comunicações. Isso levou à explosão da difusão de sambas nas rádios e à aparição de significativo número de "especialistas" em samba (FERNANDES, 2010), como os dois citados acima. Trata-se de intelectuais afeiçoados às noitadas regadas a rodas de samba, mas, também, encetados nas redações, como cronistas e jornalistas, trabalhando em diversos periódicos de suas épocas. Desse modo:

A importância desses jornalistas menores, cronistas que
se ocupavam também do futebol, dos casos policiais e do
teatro de revista, detentores de posições dominadas e
secundárias dentro das redações e dominantes junto às
agremiações carnavalescas e aos seus membros, teria sido
basicamente a de sistematizar, rotinizar e dar ao
conhecimento de um público leitor de jornal a linguagem
êmica e o universo simbólico que circundavam as
emergentes instituições promotoras de manifestações
musicais populares (FERNANDES, 2010, p. 45-46, grifo do
autor).

$\mathrm{Na}$ pena de alguns desses jornalistas, os discursos ficaram mais ferinos. Além da observação da narrativa de Orestes Barbosa, que subsumiu a importância da cepa de sambistas baianos em detrimento do pessoal carioca, oriundo da escola do Estácio de Sá (FERNANDES, 2010), existiram jornalistas que ascenderam hierarquizações e ataques diretos em suas colunas, afirmando ser o samba carioca esteticamente superior. Em trecho de matéria do Jornal Diário Carioca, 7 de março de 1934, com o título Carmem Miranda, o colunista Piagrino elevou o samba carioca e rebaixou as outras vertentes: “[...] O samba carioca tem modalidade ou rythmo diferente do samba puramente tradicional do Brasil. Um é a estilização, enquanto o outro é a barbárie [...]"(PIAGRINO, p. 7, 1934).

A construção de uma autoimagem sempre está balizada em função do outro. Não é possível produzi-la sem fazer referência ao outro (WOODWARD, 2009). O colunista Piagrino, em sua colocação, buscou tecer um código simbólico no qual a valorização extrema de um estilo de samba, encontrado no Rio de Janeiro, o levou a considerá-lo como possuindo mais 
"modalidade" e "ritmo" que os outros tipos de samba regional. Estes são os atributos semânticos encontrados para efetuar um processo de distinção, de distanciamento, construindo o conjunto de elementos que referenciam uma autoimagem carioca, impressa nesse samba moderno e esteticamente sofisticado, ao contrário das outras vertentes "tradicionais", consideradas por ele como menos desenvolvidas e esteticamente inferiores. Nesse sentido, as representações atribuídas ao samba carioca, feitas pelos agentes envolvidos em sua exaltação - a narrativa de seu nascimento, o destaque para os sambistas cariocas, a exaltação da cidade do Rio de Janeiro - são substratos das práticas de enunciados que demarcam a efetuação de uma identidade específica.

Esse contexto de valorização de determinado estilo de samba em detrimento de outros pode ser observado ainda hoje, onde Lima (2013) ressalta a presença de narrativas que jogam com a oposição entre moderno e tradicional, urbano e rural, ou com estilos de produção de samba inseridos ou não na teia comercial da indústria do disco e da difusão midiática mais ampla. Disso pode-se extrair uma reflexão acerca do lugar ocupado entre Rio de Janeiro e Bahia, na medida em que o lugar de centralidade cultural atribuído ao primeiro permite a criação de narrativas sobre a Bahia como "lugar de reserva de autenticidade, germe do samba carioca e 'trabalho acústico' extinto" (LIMA, 2013, p. 130). Por outro lado, como coloca o autor, o caráter etapista atribuído ao processo narrativo histórico sobre o samba, estabelece não somente um lugar específico ao Rio de Janeiro e à Bahia, dentro de um processo de configuração da identidade nacional, mas reforça um lugar na conformação da memória nacional para paradigmas estereotipados sobre uma negritude carioca e baiana:

[...] se a Bahia é símbolo de pureza, autenticidade e matriz do que seria nacional, a negritude baiana ocupa um lugar na tradição ao mesmo tempo em que revigora relações sociais arcaicas e hierarquias raciais. Se o Rio de Janeiro abrigou e expressou, de modo exemplar, o programa de modernização política, social e cultural defendido para o Brasil, a negritude carioca, ao aderir a esse programa, modernizada, nacionalizada, orgulhosa do seu papel nessa trama, elaborou e apresentou uma síntese do samba que lhe deu sustentação como tal (LIMA, 2013, p. 131-132). 
Se por um lado o samba carioca goza de boa exposição e valorização, o samba de roda, por sua vez, tem sido alvo de políticas de preservação histórica que têm apontado termos valorativos como "folclórico", "rústico" ou "primitivo", como chaves narrativas que aprofundam a realidade de desvalorização dessa manifestação musical. Oriundo principalmente da região do Recôncavo da Bahia, o samba de roda é característico, de acordo com o Dossiê IPHAN; 4 - Samba de roda do Recôncavo baiano (2006), de formas culturais que podem ser encontradas desde o século XVII. É fundamentado pela formação de uma roda de músicos que entoam um verso principal, chamado chula, e obtém respostas a tais versos de outros integrantes da roda, onde sempre há sambadeiras que coreografam com o corpo e, principalmente, com os pés, o miúdo. passos miúdos executados que caracterizam a dança específica ao samba de roda.

Trata-se de uma forma cultural significativamente incorporada aos valores e ao universo sociocultural dos negros, trazendo, de acordo com o Dossiê, uma mescla com outras contribuições culturais, porém, revelando-se como uma forma de expressão cultural de brasileiros afrodescendentes, que se reconhecem como tal. O samba de roda foi posto em perspectiva, no Dossiê, como construto tradicional dos sambadores e sambadeiras do Recôncavo, constituindo-se como objeto de preocupação institucional para a manutenção de sua continuidade. Nesse sentido, o samba de roda foi lançado como candidato a tornar-se patrimônio imaterial da humanidade na terceira edição do programa da UNESCO, intitulado Proclamação das Obras-Primas do Patrimônio Oral e Imaterial da Humanidade. O título materializou-se em 2005, embora tenha sido registrado no Livro de Registro das Formas de Expressão, do IPHAN, no ano de 2004. Desse modo, uma das preocupações presentes na documentação levantada no Dossiê sobre o samba de roda tem sido o discurso corrente na sociedade e nos meios midiáticos sobre processos de valorização e reconhecimento do samba de roda:

As ideias preponderantes no Brasil sobre as relações entre música popular e música folclórica estabelecem que esta última é a raiz, uma espécie de sobrevivência anacrônica, na qual a primeira se inspira e se vivifica. Isso pode ser notado no tipo de reconhecimento verbal que é dado ao samba de roda tradicional nos meios de comunicação de massa, reverenciado, em palavras, mas, considerado primitivo, rústico. [...] A percepção atual de uma parte significativa dos sambadores do Recôncavo é a de que seu 
samba de roda é desvalorizado pela sociedade. [...] É um problema cuja solução exige uma longa batalha de ideias e luta contra preconceitos arraigados [...] (IPHAN, 2006, p. 75-76).

Esse tipo de "reconhecimento" exposto no trecho acima, dado a determinado estilo de samba como "folclórico" ou "rústico", dentro de uma dicotomia moderno/tradicional, dimensiona preconceitos que se colocam a partir de concepções que passam a reproduzir estigmas. Não somente o samba de roda, mas outras manifestações regionais que estão fora do circuito de difusão comercial, passam a ser vistas como rústicas ou primitivas. Esse tipo de posição discriminatória diante de tais manifestações culturais pode ser evidenciada quando, no Jornal do Comércio, em matéria intitulada Grupo Molejo, 7-13 de dezembro de 1997, um integrante desse grupo carioca de pagode lança: "O samba baiano não é samba, é samba de roda".

O Rio de Janeiro, desde a abolição da escravidão, tem recebido grande contingente de população negra, oriunda de vários lugares, inclusive da Bahia (LIMA, s/d.). Essa comunidade negra baiana contribuiu com suas experiências estéticas, as quais foram aproveitadas na gestação do samba carioca. No entanto, enunciados como os do pagodeiro carioca acima evidenciam certo desprezo e, talvez, algum desconhecimento quanto à importância do samba de roda para a própria realidade do samba urbano carioca e do recente pagode do Rio de Janeiro. Se de um lado é possível observar enunciados de jornalistas e músicos alinhados à detração ou à desvalorização de tais manifestações culturais, há, por outro lado, a atuação do IPHAN, interessado na valorização destas, dada a sua preocupação com processos de patrimonialização. Importante considerar ainda a desvantagem do samba de roda diante do paradigma que rege o cenário cultural soteropolitano, onde predomina o âmbito da produção de mega-eventos, com grandes margens de lucro, voltados, majoritariamente, para a edição anual do carnaval baiano, ofuscando, de acordo com Döring (2013, p. 150): “[...] práticas e expressões estéticas complexas, diversificadas e autênticas, nos respectivos ambientes socioculturais".

O samba de roda informou sua influência às práticas dos sambistas na constituição do samba carioca, mas também informou muitos de seus elementos característicos ao pagode baiano. Lima (2016) coloca que este se trata de um estilo musical muito produzido e consumido por populações negras em situação social precária, que se constituiu por uma interface de 
repertórios estéticos musicais oriundos do pagode romântico, dos sambas cariocas e de roda baiano e extramusicais, com influências da dança afro, da aeróbica, bem como da dança moderna, compondo-se como uma das expressões da experiência estética de uma música negro-africana no Brasil. Tais expressões foram alvo da indiferença ou má compreensão já entre os estudos clássicos ${ }^{8}$ sobre o negro ou a cultura negro-africana, na medida em que '“paixões ruins' como bebida, erotismo e sexo, festa e religiosidade, samba ou pagode desenfreado foram vistos como inimigos dos bons costumes e do próprio negro" (LIMA, 2016, p. 18). Nascimento (2012, p. 45) afirma que foi na relação entre o samba urbano carioca e a emergência da música urbana de massas, que, na década de 1990, o pagode carioca ascendeu e, na década seguinte surgiu, por sua vez, uma "releitura" do pagode "à moda baiana", dando surgimento a grupos como Gang do Samba, Éo Tchan, dentre outros.

De acordo com Moura (2001, p. 238), o pagode baiano e a axé music, aparecem "como denominações de estilos da música carnavalesca contemporânea de Salvador". Contudo, há discursos de jornalistas, músicos e críticos culturais, tanto no Sudeste como em outras regiões, que tendem a repisar que a variedade estilística da produção cultural baiana contemporânea confunde-se com rótulo de axé music, ou música baiana. Observam-se nitidamente narrativas de homogeneização e uniformização daquilo que, na verdade, é diverso, desconsiderando-se características identitárias de estilos musicais próprios (NASCIMENTO, 2012). A mídia de alcance amplo pouco contribui para garantir o reconhecimento dos multifacetados fazeres musicais locais com suas redes de pertencimento, gerando profundas distorções na percepção da realidade plural da cultura musical baiana (CASTRO, 2011; DÖRING, 2013).

É importante salientar que abordar o pagode, seja ele em sua manifestação carioca ou baiana, significa tocar em narrativas eivadas de preconceitos. Já na década de 1990, Fernandes (2010) observou sujeitos ligados ao mundo artístico do samba e jornalistas que se lançaram, em algum

\footnotetext{
${ }^{8}$ Trata-se de estudos feitos entre o século XIX e início do XX, por autores como Nina Rodrigues, Arthur Ramos, dentre outros, que se debruçaram sobre as sobrevivências de manifestações culturais africanas entre os afro-descendentes, no Brasil. Tais abordagens acabaram por construir uma visão infantilizada, selvagem, exótica, mágica, atrasada e/ou primitiva das práticas religiosas, da música, das festas, bem como das linguagens utilizadas entre os diversos grupos negros, presentes na sociedade brasileira.
} 
momento de suas carreiras, como detratores do pagode, diferenciando-o do samba "autêntico" ou de "raiz", enxergando duas espécies distintas de estilos musicais. O autor coloca que o jornalista e crítico musical carioca Tarik de Souza, reconhecido por possuir considerável obra sobre música popular brasileira, foi um dos primeiros a se insurgir contra a ascensão do pagode carioca, principalmente quando do sucesso do grupo Raça Negra. À medida que esse pagode carioca ia crescendo em número de grupos, crescia o contingente de seus jornalistas detratores. Este também sofreu com as alfinetadas de sambistas "consagrados" pela crítica cultural "especializada", como Chico Buarque de Hollanda, Leci Brandão, Monarco, dentre outros (TROTTA, 2006).

O pagode baiano, por sua vez, não deixou de sofrer com duras investidas, recebendo crítica musical duríssima, na medida em que era codificado ao lado de outras formas musicais relegadas a "lixo comercial" nos cadernos culturais de jornais de prestígio (FERNANDES, 2010, p. 296). Tarik de Souza, em sua obra Tem mais samba, afirmou: “[...] Entre os requebros do Tchan, a choradeira do sertanejo mauriçola e sambanejo diluidor, há que ter jogo de cintura para evitar a tentação do lucro rastaquera" (SOUZA, 2003, p. 279). Observa-se, no discurso negativo do jornalista, que o pagode baiano, além de ser considerado mais uma manifestação musical aferrada ao mercado musical de lucro rápido, é colocado ao lado de outros estilos musicais que gozam de entrada significativa na indústria das gravadoras. O discurso, nesse caso, toma um aspecto de ojeriza a esses estilos que angariaram sucesso junto ao mercado musical. Também o jornalista Pedro Alexandre Sanches, que produziu a obra Tropicalismo: decadência bonita do samba, acusando Caetano Veloso e o movimento tropicalista de serem os principais promotores da decadência do samba, na sua concepção nacional-carioca, reúne, em sua coluna, no Jornal Folha de São Paulo, o ataque à dimensão mercadológica de alguns gêneros musicais e dúvidas sobre qualidade técnica da música:

No Império Unificado do Brasil Popular, todo mundo tem
a mesma cara. O tripé em que se finca atualmente o
mercado musical nacional - e não a música nacional, se
se puder diferenciar - todos se reconfiguram num
exército de mutantes descarados. Axé, pagode e música
sertaneja, as pernas do tripé, se alimentam e se
retroalimentam com reciprocidade. Até a Carla Perez se
pendura na aba do moço desta banda, SPC. Mas é mais
gosmento que a coluna social de "Caras". Quando quer ser
romântica, essa "banda de pagode" fica sertaneja; quando 
namora uma rumbinha, parece o Latino; para "abrasileirar" o rhythm `n` blues norte-americano, faz versão de pop negro melado - e fica parecido com Ivete Sangalo querendo cantar soul music com voz de pombagira (Folha de S. Paulo, 17/9/1999).

Observa-se um reducionismo nessa passagem, onde qualquer ritmo baiano transfigura-se em axé e onde o preconceito contra a música baiana se dá comparando-a ao pagode feito no Rio de Janeiro e à música sertaneja. A dançarina Carla Perez, do grupo É o Tchan, e Ivete Sangalo são colocadas no mesmo balaio, como se fossem apenas representantes do axé music, todas com “a mesma cara". Nesse sentido, Nascimento (2012, p. 55) aborda tal generalização colocando que o axé music gera significados que “[...] além de acionar esse sentido reificado e naturalizado pelo seu uso repetido e indiscriminado, servem para rotular uma produção geográfica, ou seja, de artistas baianos, do que propriamente para nomear um gênero musical". Não bastassem os ataques de jornalistas de outras regiões, o pagode baiano ainda recebe duras críticas do próprio meio artístico baiano. Este foi alvo, por exemplo, de impropérios irados da cantora Margareth Meneses:

[...] Eu já tive oportunidade de fazer um show em um lugar, aqui mesmo em Salvador onde tinha outra banda de pagode que tocaria depois de mim. Eu cantei samba reggae, eu cantei reggae, aliás o meu repertório é assim, eu cantei MPB e o povo não reagia. O povo só reagia à quebradeira, aquela coisa ridícula. Desculpe, mas eu acho aquilo ridículo essa exposição, a falta de postura mesmo, quando você mobiliza uma comunidade para consumir porcaria [...] A comunidade, a população devia expressar seu desejo melhor, de querer ver uma música melhor, de querer ver sua comunidade melhor representada [...] (GALDEA, 2009).

Parcelas do jornalismo nativo também não deixaram por menos, com críticas de teor elitista e moralista sobre a manifestação desse pagode. Nascimento (2012) afirma que jornalistas destilaram seu preconceito a partir de narrativas cujas representações pontuaram o pagode baiano e seus participantes pela vulgaridade, desqualificando-os a partir de estereótipos bem delimitados. Nesse caso, de acordo com o autor, desqualificam-se as roupas, os corpos e os cabelos, seus hábitos e formas de socialização e vivência de seus corpos. A produção artística é vista como "baixa cultura" ou "cultura da baixaria" (NASCIMENTO, 2012, p. 139). Para determinados setores sociais 
afinados com outras representações de arte e cultura, nota-se um interesse aberto em estigmatizar, ou seja, trata-se de “[...] uma maneira de 'desidentificar' os grupos remetendo para o sinal negativo de gangues, desordeiros, enfim, para toda sorte de construções discursivas negativas construídas pelos 'brancos' ou 'ricos' sobre 'os negros', 'os trabalhadores pobres'” (NASCIMENTO, 2012, p. 140). Retorna-se, com isso, a Silva (2009, p. 74), onde "a diferença é aquilo que o outro é": há a tendência a tomar o que somos como referência e norma a partir de onde descrevemos e avaliamos aqueles que não somos.

Foi tomando suas próprias referências culturais como norma que os jornalistas citados acima, bem como a cantora Margareth Meneses, puseramse a criticar o pagode baiano e seus apreciadores. Apropriando-se da abordagem de Chartier (1991), pode-se afirmar que esses sinais negativos destacados balizam-se, nessas narrativas, por representações específicas de determinados setores sociais, que se colocam em conflito com as formas de representação de identidades de setores pobres, proletários e negros baianos. Promove-se, desse modo, a reprodução de estereótipos e estigmas a determinadas práticas culturais em detrimento de outras.

\section{Conclusão}

Como foi explicitado acima, no início do XX, o Rio de Janeiro foi palco de transformações políticas e socioculturais, desencadeando novas estéticas musicais e a ascensão de um pujante mercado fonográfico e de radiofonia. Nesse contexto, disputas entre gerações de músicos negros buscou consolidar uma identidade e uma tradição sambista carioca, promovendo tensões com os sambistas baianos. Com isso, observaram-se provocações e preconceitos contra a Bahia e o grupo dos baianos nas músicas de alguns sambistas cariocas.

Entre os intelectuais êmicos citados, observou-se que se, por um lado, determinada narrativa subsumiu a contribuição do samba de roda baiano, apagando-o da história do samba do Rio de Janeiro; por outro, um discurso evolucionista ancorou o samba de roda como primordial, rural, destinado a civilizar-se em outro lugar e em outro contexto, como foi o caso da abordagem de Vagalume, em seu livro. Ademais, observaram-se ataques preconceituosos por parte de jornalistas, buscando sobrepor o samba carioca 
às outras vertentes regionais. Assim, levou-se a se considerar as codificações semânticas interessadas em demarcar distinção e distanciamento, que referenciaram o samba carioca como moderno e sofisticado, acima de outros estilos de samba. Por outro lado, ainda hoje, observa-se menos exposição e valorização do samba de roda quando comparado à versão comercial carioca. Tais manifestações regionais continuam sendo reportadas, pelos meios de comunicação de massa, como primitivas ou rústicas, atribuindo-se à negritude baiana o lugar da manutenção de valores arcaicos.

$\mathrm{O}$ pagode baiano, por sua vez, tem sido alvo do preconceito de jornalistas e músicos. A desqualificação abrange desde a crítica à sua dimensão mercadológica, sendo colocado no mesmo rótulo de música baiana, ou axé music, até aos usos e práticas do corpo, formas de socialização e vivência. Uma dimensão elitista e classista do preconceito se construiu pela visão de que tais manifestações constituem uma espécie de baixa cultura. A partir de discursos negativos construídos contra as expressões culturais de setores sociais empobrecidos e negros da sociedade baiana, promoveu-se a reprodução discursiva de estereótipos e estigmas, cuja dimensão preconceituosa perdura no tempo.

\section{Referências:}

BARBOSA, Orestes. Samba. Rio de Janeiro: Funarte, 1978.

BRASIL. Instituto do Patrimônio Histórico e Artístico Nacional. Samba de roda do Recôncavo baiano(Dossiê Iphan; 4). Brasília: Iphan, 2006.

CASTRO, Armando A. Axé music: mitos, gestão e world music. In: MOURA, Milton. A larga barra da baía: essa província no contexto do mundo [online]. Salvador: EDUFBA, 2011, p. 196-237.

CASTRO, Jonatas Dias de. Samba. Jornal do Brasil, Rio de Janeiro, p. 18, 3 jan. 1937.

CHARTIER, Roger. O Mundo como Representação. Estudos Avançados, São Paulo, v. 5, n. 11, p. 173-191, abr. 1991.

CUNHA, Maria Clementina Pereira. De sambas e passarinhos: as claves do tempo nas canções de Sinhô. In: CHALHOUB, Sidney; NEVES, Margarida de Souza; PEREIRA, Leonardo Affonso de Miranda (Org.). História em coisas miúdas: capítulos de história social da crônica no Brasil. Campinas, Unicamp, 2005. 
DÖRING, Katharina. Samba de roda: visibilidade, consumo cultural e estética musical. In: Pontos de Interrogação, Alagoinhas, v. 3, n. 2, jul./dez. 2013.

FERNANDES, Dmitri Cerbocini. A inteligência da música popular. a "autenticidade" no samba e no choro. 2010. $414 \mathrm{f}$. Tese (Doutorado em Ciências Sociais) - Faculdade de Filosofia, Letras e Ciências Humanas, Universidade de São Paulo, São Paulo, 2010.

GALDEA, João Gabriel. Pagode é uma coisa ridícula, diz Margareth Menezes. 2009. Disponível em: <http://www.youtube.com/watch?v=Yelk6faobP0>. Acesso em: 9 jun. 2018.

GOFFMAN, Erving. Estigma: notas sobre a manipulação da identidade deteriorada. 4 ed. LTC: 1988.

GUIMARÃES, Antônio Sérgio A. O preconceito contra os baianos. In: Congresso Internacional da Latin American Studies Association (LASA), 2000, Miami. Disponível em: $<$ http://lasa.international.pitt.edu/Lasa2000/Guimaraes.PDF>. Acesso em: 2 de jun. 2018.

GUIMARÃES, Francisco (VAGALUME). Na roda do samba. Rio de Janeiro: Typ. São Benedicto, 1933.

HALL, Stuart. Codificação/decodificação. In: SOVIK, Liv (Org.). Da diáspora: identidades e mediações culturais. Belo Horizonte: Ed. UFMG / Brasília: Representação da UNESCO no Brasil, 2003.

HALL, Stuart. Identidade cultural na Pós-modernidade. Rio de Janeiro: DP\&A, 2011.

HOBSBAWM, Eric J.; RANGER, Terence. A invenção das tradições. São Paulo: Paz e Terra, 2014.

LEAL, Guilherme Carréra Campos. Nos bastidores do samba urbano: notas sobre origem, conflitos e apropriações. In: Sonora, v. 6, n. 11, 2016.

LIMA, Ari. Do samba carioca urbano e industrial ao samba nacional e mestiço. In: Artcultura, Uberlândia, v. 15, n. 26, p. 121-135, jan./jun. 2013.

LIMA, Ari. O Rio para os baianos. A Bahia para os cariocas: especulações em torno de identidades geradas no samba carioca no início do século e no samba baiano nos anos 90. Salvador: Projeto S.A.M.BA, UFBA, s/d.

LIMA, Ari. Uma crítica cultural sobre o pagode baiano. a música que se ouve, se dança e se observa. Salvador: Pinaúma, 2016. 
MONTEIRO, Bianca Miucha Cruz. Sinhô: a poesia do rei do samba. 2010. 223 f. Dissertação (Mestrado em História Social) - Faculdade de História, Universidade Federal Fluminense, Niterói, 2010.

MOURA, Milton Araújo. Carnaval e baianidade: arestas e curvas na coreografia de identidades do carnaval de Salvador. 2001. 364 f. Tese (Doutorado em Comunicação e Cultura Contemporânea) - Faculdade de Comunicação, Universidade Federal da Bahia, Salvador, 2001.

NASCIMENTO, Clebemilton. Pagodes baianos: entrelaçando sons, corpos e letras. Salvador: EDUFBA, 2012.

OLIVEIRA, Janine Neves de. Os orfeus da "Aquarela": um estudo sobre a questão racial brasileira a partir do Batuque Afro-brasileiro de Nelson Silva. 2016. 207 f. Dissertação (Mestrado em Ciências Sociais) - Instituto de Ciências Humanas, Universidade Federal de Juiz de Fora, Juiz de Fora, 2016.

POLLAK, Michael. Memória e identidade social. In: Estudos Históricos, Rio de Janeiro, v. 5, n. 10, p. 200-212, 1992.

PIAGRINO. Carmen Miranda. Diário Carioca, Rio de Janeiro, p. 7, mar. 1934.

ROMO, Anadelia. O que é que a Bahia representa? O Museu do Estado da Bahia e as disputas em torno da definição da cultura baiana. In: Afro-Ásia, n. 39, p. 115-151, 2010.

SANCHES, Pedro Alexandre. Tropicalismo: decadência bonita do samba. São Paulo: Boitempo, 2000.

SANDRONI, Carlos. Feitiço decente transformações do samba no Rio de Janeiro (1917-1933). Rio de Janeiro: Zahar, 2001.

SEM AUTOR. Grupo Molejo. Jornal do Comércio, Rio de Janeiro, p. 3-7, 7-13 dez. 1997.

SEM AUTOR. “Quem nasce na Bahia é bamba... ”. O Imparcial, p. 1, 8 mar. 1935.

SILVA, Tomaz Tadeu da. (Org.). Identidade e diferença: a perspectiva dos estudos culturais. Petrópolis: Vozes, 2009.

SODRÉ, Muniz. Samba: o dono do corpo. Rio de Janeiro: Mauad, 1998.

SOUZA, Tarik de. Tem mais samba: das raízes à eletrônica. São Paulo: Editora 34, 2003. 
TROTTA, Felipe da Costa. Samba e mercado de música nos anos 1990. 259 f. 2006. Tese (Doutorado em Comunicação e Cultura) - Escola de Comunicação, Universidade Federal do Rio de Janeiro, 2006.

WOODWARD, Kathryn. Identidade e diferença: uma introdução teórica e conceitual. In: SILVA, Tomaz Tadeu da. (Org.). Identidade e diferença: a perspectiva dos estudos culturais. Petrópolis: Vozes, 2009.

Recebido em: 31/10/2018

Aprovado em: 04/12/2018 